\title{
Co-treatment of landfill leachate and municipal wastewater using the ZELIAC/zeolite constructed wetland system
}

\begin{abstract}
Constructed wetland $(\mathrm{CW})$ is a low-cost alternative technology to treat wastewater. This study was conducted to co-treat landfill leachate and municipal wastewater by using a $\mathrm{CW}$ system. Typha domingensis was transplanted to $\mathrm{CW}$, which contains two substrate layers of adsorbents, namely, ZELIAC and zeolite. Response surface methodology and central composite design have been utilized to analyze experimental data. Contact time (h) and leachate-to-wastewater mixing ratio $(\% ; \mathrm{v} / \mathrm{v})$ were considered as independent variables. Colour, COD, ammonia, nickel, and cadmium contents were used as dependent variables. At optimum contact time $(50.2 \mathrm{~h})$ and leachate-to-wastewater mixing ratio $(20.0 \%)$, removal efficiencies of colour, COD, ammonia, nickel, and cadmium contents were $90.3 \%, 86.7 \%$, $99.2 \%, 86.0 \%$, and $87.1 \%$, respectively. The accumulation of $\mathrm{Ni}$ and $\mathrm{Cd}$ in the roots and shoots of T. domingensis was also monitored. Translocation factor (TF) was $>1$ in several runs; thus, Typha is classified as a hyper-accumulator plant.
\end{abstract}

Keyword: Co-treatment; Landfill leachate; RSM; Wetland; ZELIAC; Zeolite 